\title{
Editorial: Advances in the Bio- and Chemo-Catalytic Conversion of Biomass Components Into Biofuels and Value-Added Chemicals
}

\author{
Kai Yan ${ }^{1 *}$, Chunbao Charles $X u^{2 *}$, Guoqing Guan ${ }^{3 *}$ and $X u W u^{4 *}$ \\ ${ }^{1}$ Guangdong Provincial Key Laboratory of Environmental Pollution and Remediation Technology, School of Environmental \\ Science and Engineering, Sun Yat-sen University, Guangzhou, China, ${ }^{2}$ Department of Chemical and Biochemical Engineering, \\ Western University, London, ON, Canada, ${ }^{3}$ Institute of Regional Innovation, Hirosaki University, Aomori, Japan, ${ }^{4}$ School of \\ Chemistry and Chemical Engineering, Taiyuan University of Technology, Taiyuan, China
}

Keywords: homogeneous catalysis, heterogeneous catalysis, valorization, lignocellulose, biofuels, value-added chemicals, biocatalytic system

Editorial on the Research Topic

Advances in the Bio- and Chemo-Catalytic Conversion of Biomass Components Into Biofuels and Value-Added Chemicals

Edited by:

Georg M. Guebitz,

University of Natural Resources and

Life Sciences Vienna, Austria

${ }^{*}$ Correspondence:

Kai Yan

yank9@mail.sysu.edu.cn

Chunbao Charles Xu

cxu6@uwo.ca

Guoqing Guan

guan@hirosaki-u.ac.jp

Xu Wu

wuxu@tyut.edu.cn

Specialty section:

This article was submitted to

Industrial Biotechnology,

a section of the journal

Frontiers in Bioengineering and

Biotechnology.

Received: 03 September 2021

Accepted: 06 October 2021

Published: 18 October 2021

Citation:

Yan K, Xu CC, Guan G and Wu X (2021) Editorial: Advances in the Bioand Chemo-Catalytic Conversion of Biomass Components Into Biofuels and Value-Added Chemicals. Front. Bioeng. Biotechnol. 9:769995.

doi: 10.3389/fbioe.2021.769995

\section{INTRODUCTION}

Biomass has been identified as a renewable alternative to fossil resources in producing promising transportation biofuels as well as highly valuable products (Huber et al., 2006; Alonso et al., 2012; Hu et al., 2021). Many crucial products, including fuels, fine chemicals and plastics, have been generated from the inedible portion of biomass resources and the fast increased need has sparked efforts on such transformation (Corma et al., 2007; Julis et al., 2010). The past several decades have witnessed a fast development of robust catalysts, various catalytic system, and catalytic pathways for converting lignocellulose into many useful products, making the valorization of renewable biomass into reality (Zhang et al., 2013; Zhang et al., 2020; Zhao et al., 2021). Catalyst development play an important role in achieving this goal. Over the last a few decades, different types of catalysts (e.g., metal nanoparticles, enzyme, acidic or basic candidates) have been frequently designed and investigated (Alonso et al., 2013; Nanda et al., 2016; Hu et al., 2019; Liu et al., 2021). This special issue concentrates on the pretreatment of biomass using enzymes, anaerobic digestion of naive source, various factors on the thermal pyrolysis, value-added chemicals synthesis and degradation.

\section{BIOMASS PRETREATMENT}

The complex composition of naïve biomass makes it difficult to be utilized. Pretreatment is crucial for the further utilization. Saddler and coworkers reported the improved activity from the use of enzymes in tuning the hydrolysis of cellulose through introducing acid functions into the structure of lignin for the pretreatment. They found that the use of $16 \% \mathrm{Na}_{2} \mathrm{SO}_{3}$ or $32 \% \mathrm{C}_{2} \mathrm{H}_{6} \mathrm{Na}_{4} \mathrm{O}_{12}$ into the pulp would not induce clear delignification exhibiting the similar behavior to the proper dosage of $\mathrm{HSO}_{3}{ }^{-}$and $\mathrm{HCO}_{3}{ }^{-}$into the structure of lignin. It provides a new way to utilize enzymes for biomass pretreatment. 


\section{ANAEROBIC DIGESTION}

During the anaerobic digestion of biomass, many factors would influence the efficiency. Various efforts have been focused on optimization of the reaction parameters. $\mathrm{Li}$ and coworkers demonstrated that the addition of zero valent iron $(10 \mathrm{~g} / \mathrm{L})$ could hamper the anaerobic digestion of raw biomass. They found that proper amount of zero valent iron would promote the anaerobic digestion activity. An interesting finding of their study was that zero valent iron could largely enhance the methanogenic rate in 6 days, but decreased the total methane yield by $10.3 \%$. By studying varying effects, they got the conclusion that the behavior was impacted by features of substrate and component ratio.

\section{BIOMASS CATALYTIC PYROLYSIS}

Pyrolysis is one of crucial tools to upgrade biomass into value-added products. Bi and coworker studied the cooperation effects of catalyst component on the pyrolysis process compared with the unitary candidate in the microwave reactor. They investigated the deoxygenation behavior and reaction kinetics including pyrolysis kinetics and pathway of biomass-derived monomers (i.e., cellulose, hemicellulose, and lignin). They found the activation energy of 10KP/ 10 Bento and $10 \mathrm{KP} / 10 \mathrm{Clino}$ (the mixture of $10 \% \mathrm{~K}_{3} \mathrm{PO}_{4}$ plus $10 \%$ clinoptilolite) was a little lower or close to those of other candidates at 30 wt.\%. They got the conclusion that catalyst mixtures could enhance the catalytic activity clearly, which is attractive to lower the synthesis cost of bio-oils and biochar.

\section{DEGRADATION OF SIDE PRODUCTS}

Biomass-derived bisphenol A (BPA) is a widely utilized fine chemical in various areas (e.g., medicine and organic

\section{REFERENCES}

Alonso, D. M., Wettstein, S. G., and Dumesic, J. A. (2012). Bimetallic Catalysts for Upgrading of Biomass to Fuels and Chemicals. Chem. Soc. Rev. 41, 8075-8098. doi:10.1039/c2cs35188a

Alonso, D. M., Wettstein, S. G., and Dumesic, J. A. (2013). Gamma-valerolactone, a Sustainable Platform Molecule Derived from Lignocellulosic Biomass. Green. Chem. 15, 584-595. doi:10.1039/c3gc37065h

Corma, A., Iborra, S., and Velty, A. (2007). Chemical Routes for the Transformation of Biomass into Chemicals. Chem. Rev. 107, 2411-2502. doi:10.1021/cr050989d

Hu, D., Xu, H., Yi, Z., Chen, Z., Ye, C., Wu, Z., et al. (2019). Green CO2Assisted Synthesis of Mono- and Bimetallic Pd/Pt Nanoparticles on Porous Carbon Fabricated from Sorghum for Highly Selective Hydrogenation of Furfural. ACS Sustainable Chem. Eng. 7, 15339-15345. doi:10.1021/ acssuschemeng.9b02665

Hu, D., Zhang, M., Xu, H., Wang, Y., and Yan, K. (2021). Recent advance on the Catalytic System for Efficient Production of Biomass-Derived 5-hydroxymethylfurfural. Renew. Sustainable Energ. Rev. 147, 111253. doi:10.1016/j.rser.2021.111253

Huber, G. W., Iborra, S., and Corma, A. (2006). Synthesis of Transportation Fuels from Biomass: Chemistry, Catalysts, and Engineering. Chem. Rev. 106, 4044-4098. doi:10.1021/cr068360d synthesis), while the residual BPA is difficult to be degraded by nature. Yan and coworkers reported a photocatalytic route to degrade BPA using a porous $\mathrm{ZnO}$ photocatalyst. The effects of various parameters were investigated and porous $\mathrm{ZnO}$ photocatalyst can remove 99\% BPA in $1 \mathrm{~h}$. The results of EPR analysis confirmed that $\mathrm{h}^{+}, \cdot \mathrm{O}^{-2}$, and $\mathrm{e}^{-}$played an important role in the removal efficiency. This study offers a photocatalytic route to deal with biomass-derived chemicals.

\section{SYNTHESIS OF BIOMASS-DERIVED CHEMICALS}

A variety of biomass-derived chemicals can be selectively produced from biomass, among which cyclopentanol can be used as a versatile eco-friendly solvent in various applications. Zhang and coworkers fabricated a bimetallic Ru-Mo catalyst for hydrogenation-rearrangement reactions of furfurals, achieving $89.1 \%$ cyclopentanol yield using $1 \% \mathrm{Ru}-2.5 \% \mathrm{Mo} / \mathrm{CNT}$ prereduced at $600^{\circ} \mathrm{C}$. The weak acidity and strong hydrogenation activity of the bimetallic Ru-Mo catalyst were found to be important for the synthesis of cyclopentanol from furfural-like compounds.

\section{AUTHOR CONTRIBUTIONS}

$\mathrm{KY}$ is the leading editor of the special issue and wrote the draft of this editorial. CX and GG help revise and polish. All authors proof-read the manuscript.

\section{ACKNOWLEDGMENTS}

Topic Editors specially thank all authors in this especial issue.

Julis, J., Hölscher, M., and Leitner, W. (2010). Selective Hydrogenation of Biomass Derived Substrates Using Ionic Liquid-Stabilized Ruthenium Nanoparticles. Green. Chem. 12, 1634-1639. doi:10.1039/ c004751a

Liu, B., Xu, S., Zhang, M., Li, X., Decarolis, D., Liu, Y., et al. (2021). Electrochemical Upgrading of Biomass-Derived 5-hydroxymethylfurfural and Furfural over Oxygen Vacancy-Rich NiCoMn-Layered Double Hydroxides Nanosheets. Green. Chem. 23, 4034-4043. doi:10.1039/ dlgc00901j

Nanda, M. R., Yuan, Z., Qin, W., and Xu, C. (2016). Recent Advancements in Catalytic Conversion of Glycerol into Propylene Glycol: A Review. Catal. Rev. 58, 309-336. doi:10.1080/01614940.2016.1166005

Zhang, M., Liu, Y., Liu, B., Chen, Z., Xu, H., and Yan, K. (2020). Trimetallic NiCoFe-Layered Double Hydroxides Nanosheets Efficient for Oxygen Evolution and Highly Selective Oxidation of Biomass-Derived 5Hydroxymethylfurfural. ACS Catal. 10, 5179-5189. doi:10.1021/ acscatal.0c00007

Zhang, Z., Xin, L., Qi, J., Chadderdon, D. J., and Li, W. (2013). Supported Pt, $\mathrm{Pd}$ and $\mathrm{Au}$ Nanoparticle Anode Catalysts for Anion-Exchange Membrane Fuel Cells with Glycerol and Crude Glycerol Fuels. Appl. Catal. B: Environ. 136-137, 29-39. doi:10.1016/ j.apcatb.2013.01.045 
Zhao, Z., Jiang, Z., Xu, H., and Yan, K. (2021). Selective Production of Phenol-Rich Bio-Oil from Corn Straw Waste by Direct Microwave Pyrolysis without Extra Catalyst. Front. Chem. 9, 700887. doi:10.3389/fchem.2021.700887

Conflict of Interest: The authors declare that the research was conducted in the absence of any commercial or financial relationships that could be construed as a potential conflict of interest.

Publisher's Note: All claims expressed in this article are solely those of the authors and do not necessarily represent those of their affiliated organizations, or those of the publisher, the editors and the reviewers. Any product that may be evaluated in this article, or claim that may be made by its manufacturer, is not guaranteed or endorsed by the publisher.

Copyright (c) $2021 \mathrm{Yan}, \mathrm{Xu}$, Guan and Wu. This is an open-access article distributed under the terms of the Creative Commons Attribution License (CC BY). The use, distribution or reproduction in other forums is permitted, provided the original author(s) and the copyright owner(s) are credited and that the original publication in this journal is cited, in accordance with accepted academic practice. No use, distribution or reproduction is permitted which does not comply with these terms. 